\title{
Evaluation of Flow Resistance in Gravel-Bed Channels with Bed-Load Transport by using Multi- Gene Genetic Programming
}

Satish Kumar ( $\nabla$ satishserly@gmail.com )

NIT Rourkela: National Institute of Technology Rourkela

Arpan Pradhan

Christ University

Jnana Ranjan Khuntia

CBIT: Chaitanya Bharathi Institute of Technology

Kishanjit Kumar Khatua

NIT Rourkela: National Institute of Technology Rourkela

\section{Research Article}

Keywords: Friction factor, Open Channels, Gravel-bed, Bedload Transport, Multi-Gene genetic programming

Posted Date: January 27th, 2022

DOI: https://doi.org/10.21203/rs.3.rs-1134495/v1

License: (c) (i) This work is licensed under a Creative Commons Attribution 4.0 International License. Read Full License 


\section{Abstract}

Evaluation of flow resistance is necessary for the computation of conveyance capacity in open channels. For the case of channels with bedload conditions, the significance of the friction factor is of paramount importance. The gravel-bed channel response for a bedload transport condition in terms of flow resistance is distinct from that of a fixed bed and requires a different evaluation technique. The paper studies the different empirical approaches by various authors to determine the friction factor under bedload transport conditions and proposes an expression using genetic programming to derive the same. Flow resistance in the bedload transport condition is affected by various hydraulic as well as geometric parameters. In the present study, the factors proposed to be influencing friction factor for such a flow condition are undertaken as bed slope, relative submergence depth, aspect ratio, Reynolds number, and Froude number. A wide range of experimental datasets is used to determine the effect of these influencing parameters. The predictability of the proposed model is compared to the various empirical equations in literature. The proposed model is observed to effectively predict the friction factor for a wide range of datasets, unlike the existing models. The evaluated value of the friction factor from different models is used to validate the conveyance capacity of a river. The developed Multi-Gene Genetic Programming (MGGP) model is observed to reasonably predict discharge in the river, signifying that the model is competent to be applied to field study, within the specified range of parameters.

\section{Introduction}

The bedload in an open channel usually refers to the sediment particles entrained into the turbulent flow of water and deposited again at a short distance in the flow direction. The movement of bedload depends on the strength of flow and the characteristics of the sediment particles. During movement, sediment particles offer resistance to the flow, often estimated as different roughness coefficients. A reliable estimation of the roughness coefficient is necessary for hydraulic analysis of the streams and evaluating change in conveyance for a particular flow condition. The measurement of flow resistance for bedload transport conditions is difficult as it depends on the strength of the flow, complex secondary flow structures, bed shear stress distribution, bed particle sizes, etc. Extensive research has been carried out on gravel-bed streams, with movable channel bed and various expressions for Darcy-Weisbach friction factor $f$, but for specific geometrical and hydraulic conditions, limited to the respective experimental conditions.

Assessment of the effect of bedload transport and its impact on the flow characteristic has acquired significance in the past few decades. Researchers such as Smart and Jaeggi (1983); Rickenmann (1990); Song et al. (1998); Omid et al. (2003); Gao and Abrahams (2004); Mahdavi and Omid (2004), and Campbell

et al. (2005) are a few that have analyzed the effect of moving bedload on the flow resistance. Einstein and Barbarossa (1951), Van Rijn (1982), and Wu and Wang (1999) have considered the effect of bedload in terms of an extra resistance caused due to bedforms in the case of the alluvial rivers. Meyer-Peter and Muller (1948) proposed the use of correction factors to take into account such effects. A direct effect of bedload on the increase in flow resistance with slope (varying from 3-9\%) was reported by Bathurst et al. (1982a) by calculating resistance encountered by flow over a mobile bed; compared with a fixed bed 
condition. Song et al. (1998) observed that the movable bed increases the flow resistance and is dependent on the concentration and the size of the moving particles. The bedload transport was observed to increase the friction factor by up to $50 \%$, causing an increase in depth by $14 \%$. The widely accepted view is that change in flow resistance response in mobile bedload is based on the dissipation of kinetic energy due to the collision of sediment particles and bedload, extracting momentum from the flow. Wiberg and Rubin (1989) observed that the flow resistance associated with bedload transport could reach much higher values in upper plane bed conditions than those observed with fixed bed conditions. Carbonneau and Bergeron (2000) concluded that the introduction of suspended sediment into a clean water flow can alter the turbulence intensity depending on the relative magnitude of flow and sediment transport variables.

Hu and Abrahams $(2004,2005)$ compared bedload friction factor in mobile and fixed beds and found that resistance to flow in moving bedload is more than that in fixed beds. They observed that the friction factor due to the bedload movement was $22.06 \%$ of the total resistance due to the extraction of momentum from the flow. They reported that resistance to flow is influenced by factors such as sediment concentration, relative submergence depth, particle diameter, bed slope, and Froude number. Recking et al. (2008) reported that friction factor $f$ increases with the sediment concentration in mobile bed conditions. Movable bedload conditions affect the variations in the influencing parameters, thus complicating the determination of flow resistance by employing analytical methods. In such a situation, evolutionary computing based on artificial intelligence (Al) is increasingly used in various water resources engineering branches for modeling nonlinear phenomena. Multiple studies in the literature suggest that artificial intelligence application gives close results to the real data for solutions of linear, non-linear, and other systems (Fisher et al., 1993; Amershi S. et al., 2019; Jiao and Alavi, 2020). Al's primary objective is to use computational methods to extract information from data. In recent years algorithms based on Al have been increasingly used in civil engineering and water resources (Mohammad et al., 2018; Giustolisi et al., 2008), showing a high capacity for non-linear modeling phenomena.

Gene programming is a type of artificial intelligence-based method mostly applied to solve technical problems in different engineering fields. Genetic programming (GP) is based on the Darwinian theory of natural selection used as an alternate soft computing technique. According to the classification of modeling techniques based on colors by Giustolisi et al. (2008), it is defined as the next generation of soft computing techniques, whose meaning is related to the three levels of prior information required, white-, black-, and grey-box models.

GP and its variant multi-gene GP (MGGP) can be classified as grey box techniques. Higher the physical knowledge used during the model development, the better the physical interpretation of the phenomenon that the model allows the user.

The MGGP modeling is acquiring importance and being used as an advancing computational technique in water resources engineering, for hydrological and hydraulic investigations. Azamathulla (2010), Gandomi et al. (2011), Azamathulla et al. (2013) Khozani et al. (2017), Pradhan and Khatua (2018), and Das et al. (2019) discussed implementing MGGP modeling to predict flow parameters. The MGGP approach at present has become a widely accepted computational tool in many disciplines, including civil engineering 
(Gandomi et al. 2011), neurocomputing (Peng et al. 2013), and electrical engineering (Mekhamer et al. 2012).

The main advantage of genetic programming and its variant multi-gene genetic programming (MGGP) over traditional statistical or regression methods and even other soft computing techniques is its ability to develop a compact and explicit prediction equation in different models variables without assuming a prior form of the existing relationship. The main advantage of genetic programming over regression and other soft computing techniques is its ability to generate a simplified prediction equation without considering a prior form of the existing relationship.

This paper proposes a Multi-Gene Genetic Programming (MGGP) technique to develop a reliable model for predicting flow resistance expressed as the Darcy-Weisbach friction factor for moving bedload conditions. The model is developed using the observed experimental data of various researchers and compared with traditional friction factor expressions. The developed model is verified with the authors' experimentations at the hydraulics laboratory of the National Institute of Technology Rourkela, India, and even for a natural river.

\section{Materials And Methods}

\subsection{Data Collection}

\subsubsection{Gravel-Bed Laboratory Datasets}

In total, 774 experimental flume datasets observed under equilibrium bedload transport conditions (i.e., no erosion or deposition of sediment particles on the bed occurs) have been undertaken in this study using the selection criteria of particle diameter higher than $2 \mathrm{~mm}$ and less or equal to $64 \mathrm{~mm}$ (i.e., gravel), sediment geometric standard deviation less than 1.6, and no formation of bedforms as per Liu's bedform classification(Julien, 2010). Gilbert (1914) performed experimental studies and provided 104 datasets by varying the particle size, flume dimensions, and bed slope. Cassey (1935) conducted 42 experimental observations by changing the particle size and channel bed slope. 174 combinations of experimental observations were performed by Mavis (1937) for five different particle sizes on a fixed channel width but varying longitudinal slope of the channel. Bogardi (1939) carried out 44 laboratory studies by varying width, the channel's slope, and sediment particles. Ho Pang Yung (1939) and Meyer-Peter and Muller (1948) provided 24 and 59 datasets of bedload transport conditions, respectively. Paintal (1971) conducted 37 sets of laboratory studies by changing the flume's bed slope for the different particle sizes of bed materials. Smart and Jaeggi (1983) carried out 24 experimental studies of bedload transport conditions by varying the bed-slope for three sizes of bed material. Rickenman (1990) performed 46 experiments with similar parameters as Smart and Jaeggi (1983), but for different slopes of the channel. Cao (1985) and Graf and Suszuka (1987) conducted 35 and 106 experiments respectively, on a $0.6 \mathrm{~m}$ wide flume by varying the bed-slope for different gravel sizes. Recking (2006) carried out flume experimentations on 79 combinations of discharge,bed-slope, and particle size of the bed and analysed the observational datasets of bedload conditions compiled from various laboratory studies. The different flow conditions for the 
above datasets have been tabulated in Table 2. These experiments have been performed in flumes of different widths, and where flumes are not sufficiently wide, drag due to sidewall has a significant effect on flow resistance. Therefore it becomes necessary to delineate sidewall drag from overall flow resistance from each observation from different experiments to ensure that flow resistance is calculated from gravel bed only. Accordingly, each observational dataset was delineated for the sidewall correction on consideration of the distinct exchange of momentum by gravel bed ansidewallll following Vanoni and Brooks (1975) procedure wherein the friction factor for sidewall was calculated iteratively using the Prandtl's friction law (Schlitchting 1979). Thus, the fiction factor corresponding to the flow cross-sectional area obtained after delineation is only due to the response from the gravel bed. Thus screened datasets from different flume experiments have been upscaled to represent the uniform condition and combined to make it a representative dataset for the purpose of analysis. 
Table 2

Geometric and Hydraulic flow conditions for the experimental data sets

\begin{tabular}{|c|c|c|c|c|c|c|c|}
\hline Datasets & $\begin{array}{l}\text { Discharge } \\
Q \\
\left(\mathrm{~m}^{3} / \mathrm{sec}\right)\end{array}$ & $\begin{array}{l}\text { Slope } \\
\text { So } \\
\text { (\%) }\end{array}$ & $\begin{array}{l}\text { Width } \\
\text { (m) }\end{array}$ & $\begin{array}{l}\text { Depth } \\
\text { of flow } \\
\text { (m) }\end{array}$ & $\begin{array}{l}\text { Grain Mean } \\
\text { Diameter, D } \\
(\mathrm{mm})\end{array}$ & $\begin{array}{l}\text { Density } \\
\text { of solid } \\
\text { particle } \\
\left(\mathrm{g} / \mathrm{cm}^{3}\right)\end{array}$ & $\begin{array}{l}\text { Sediment } \\
\text { concentra- } \\
\text { tion }\left(\mathrm{g} / \mathrm{m}^{3}\right)\end{array}$ \\
\hline \multirow[t]{2}{*}{ Gilbert (1914) } & $0.005-$ & $0.62-$ & $0.201-$ & $0.027-$ & 3.17,4.94, & 2.65 & 315-9700 \\
\hline & 0.032 & 2.25 & 0.402 & 0.170 & 7.01 & & \\
\hline \multirow[t]{2}{*}{ Cassey (1935) } & $0.005-$ & $0.119-$ & 0.400 & $0.027-$ & 2.46 & 2.65 & $2-1266$ \\
\hline & 0.099 & 0.509 & & 0.287 & & & \\
\hline \multirow[t]{2}{*}{ Mavis (1937) } & $0.006-$ & $0.155-$ & 0.819 & $0.0171-$ & $2.03,3.12,3.73$ & 2.66 & $1-1488$ \\
\hline & 0.078 & 1.01 & & 0.1329 & 4.18 & & \\
\hline \multirow{2}{*}{$\begin{array}{l}\text { Bogardi } \\
\text { (1939) }\end{array}$} & $0.016-$ & $1.04-$ & $0.300-$ & $0.0343-$ & 6.85,10.34, & 2.61, & 7-1010 \\
\hline & 0.064 & 2.45 & 0.823 & 0.1375 & 15.19 & 2.64 & \\
\hline \multirow{2}{*}{$\begin{array}{l}\text { Ho Pang Yung } \\
\text { (1939) }\end{array}$} & $0.016-$ & $0.128-$ & 0.399 & $0.0732-$ & 4.36,6.01, & 2.66, & $0.1--169$ \\
\hline & 0.069 & 0.504 & & 0.2463 & 6.28 & 2.70 & \\
\hline \multirow{2}{*}{$\begin{array}{l}\text { Meyer-Peter } \\
\text { and Muller } \\
\text { (1948) }\end{array}$} & $0.005-$ & $0.128-$ & $0.35-$ & 0.033- & 5.21, & 2.68 & 6-10573 \\
\hline & 4.613 & 2.27 & 1.999 & 1.092 & 28.65 & & \\
\hline \multirow[t]{2}{*}{ Paintal (1971) } & $0.02605-$ & $0.134-$ & $0.914-$ & $0.0671-$ & 2.5,7.95, & 2.65 & 0.19--348 \\
\hline & 0.25484 & 1.00 & 0.919 & 0.2134 & 22.2 & & \\
\hline \multirow{2}{*}{$\begin{array}{l}\text { Smart and } \\
\text { Jaeggi (1983) }\end{array}$} & $0.005-$ & $3.00-$ & 0.20 & $0.023-$ & $4.2,10.5$ & 2.67, & 4667- \\
\hline & 0.03 & 20.00 & & 0.083 & & 2.68 & \\
\hline \multirow{2}{*}{$\begin{array}{l}\text { Cao } \\
(1985)\end{array}$} & $0.04-$ & $0.50-$ & 0.60 & $0.058-$ & $11.5,44.3$ & 2.65 & $16-51000$ \\
\hline & 0.19 & 9.00 & & 0.217 & & 2.75 & \\
\hline \multirow{2}{*}{$\begin{array}{l}\text { Graf } \\
(1987)\end{array}$} & $0.040-$ & $0.50-$ & 0.60 & $0.07-$ & $12.2,23.5$ & 2.72 & $2-2666$ \\
\hline & 0.205 & 2.50 & & 0.26 & & 2.74 & \\
\hline \multirow{2}{*}{$\begin{array}{l}\text { Rickenmann } \\
\text { (1990) }\end{array}$} & $0.01-$ & 7.00- & 0.2 & 0.031- & 10 & $2 . .68$ & 39333- \\
\hline & 0.03 & 20.00 & & 0.085 & & & \\
\hline \multirow[t]{2}{*}{$\begin{array}{l}\text { Recking } \\
(2006)\end{array}$} & $0.0006-$ & $1.00-$ & $0.10-$ & $0.012-$ & 2.3,4.9,9.0, & 2.60 & $\begin{array}{l}4000- \\
-99111\end{array}$ \\
\hline & 0.015 & 9.00 & 0.25 & 0.075 & 12.5 & & \\
\hline
\end{tabular}

\subsubsection{New Gravel-Bed Laboratory Dataset}




\subsubsection{Experimental Setup}

Mobile bed investigations have been carried out at the Hydraulics Laboratory of the National Institute of Technology Rourkela, India. The experimental channel is fabricated on a $13 \mathrm{~m}$ long tilting flume with a width of $0.9 \mathrm{~m}$. A moving bridge arrangement is provided across the flume's width to facilitate taking measurements throughout the cross-section and along the length of the flume. Water from the overhead tank at the upstream end flows into the flume, which consequently discharges into a volumetric tank, finally flowing into an underground sump from where it is recirculated. The volumetric tank measures actual discharge flowing into the flume for every experimental condition. The schematic diagram of the water recirculation system is illustrated in Figure 1, with the channel photograph shown in Figure 2.

\subsubsection{Experimental Procedure}

Three experiments are carried out in the flume by fabricating straight rectangular channels of width $0.9 \mathrm{~m}$. Sediment feeding is done using a feeding tank fitted with a small conveyor belt equipped with an RPM controller for controlled feeding of sediment into the flume. The transported sediments are collected at the downstream end, dried, and recirculated back into the flume. The condition of plane bedload transport is achieved by varying the flume discharge, and bed slopes for a particular gravel size and hydraulic parameters are noted. Two uniformly graded bed materials are considered with mean diameters of 2.93 and $7.72 \mathrm{~mm}$. With a grain diameter of $2.93 \mathrm{~mm}$, plane bedload transport was observed with bed slope as 0.0015 and 0.002 , represented as Series I and Series II, in this paper, respectively. The Series III represents the values of parameters for bed material of $7.72 \mathrm{~mm}$ mean diameter for the condition of moving bedload observed at bed slope of 0.005 . The hydraulic parameters are illustrated in Table 1.

Table 1

Hydraulic Parameters of Experimentation at NIT Rourkela

\begin{tabular}{|c|c|c|c|c|c|}
\hline $\begin{array}{l}\text { Data } \\
\text { Series }\end{array}$ & $\begin{array}{l}\text { Slope } \\
(\mathrm{m} / \mathrm{m})\end{array}$ & $\begin{array}{l}\text { Width } \\
\text { (m) }\end{array}$ & $\begin{array}{l}D_{\text {mean }} \\
(\mathrm{mm})\end{array}$ & Discharge, $Q\left(\mathrm{~m}^{3} / \mathrm{sec}\right)$ & Depth of Flow (m) \\
\hline $\begin{array}{l}\text { Series I } \\
(12 \\
\text { sets })\end{array}$ & 0.0015 & 0.9 & 2.93 & $\begin{array}{l}0.0284,0.0384,0.0434 \\
0.0559,0.0590,0.0640 \\
0.0708,0.0813,0.0878 \\
0.0963,0.1048,0.1159\end{array}$ & $\begin{array}{l}0.0701,0.0832,0.0954 \\
0.1018,0.1091,0.1134 \\
0.1198,0.1222,0.1481 \\
0.1454,0.1582,0.1673\end{array}$ \\
\hline $\begin{array}{l}\text { Series II } \\
\text { (4 sets) }\end{array}$ & 0.002 & 0.9 & 2.93 & $\begin{array}{l}0.0765,0.07934,0.0849, \\
0.1302\end{array}$ & $\begin{array}{l}0.1219,0.1228,0.1292, \\
0.1783\end{array}$ \\
\hline $\begin{array}{l}\text { SeriesIII } \\
\text { (3 sets) }\end{array}$ & 0.005 & 0.9 & 7.72 & $0.0708,0.0793,0.0906$ & $0.0975,0.1030,0.1122$ \\
\hline
\end{tabular}

Flow Resistance Equations For Gravel-bed Channels 
Due to resistance of flow, a portion of the energy is lost to overcome it. Other factors, such as a change in velocity and flow depth, also lead to energy dissipation. The resistance models proposed by Chezy's, Manning, and Darcy-Weisbach uses this concept of energy loss due to resistance encountered in the direction of flow. The flow resistance is generally represented by the resistance coefficient in-lieu of the bed condition, such as Manning's roughness coefficient $n$, Chezy's coefficient $C$, and the Darcy-Weisbach friction factor $f$.

The Darcy-Weisbac relation is usually preferred in research experiments as it is non-dimensional, contrary to $C\left[\mathrm{~L}^{1 / 2} \mathrm{~T}^{-1}\right]$ and $n\left[\mathrm{~L}^{1 / 3} \mathrm{~T}\right]$ and the results obtained for a given experimental set can be directly extended to other flow conditions.

The flow resistance equation for the Darcy-Weisbach friction factor $f$ in the condition of uniform flow in open channels is represented as,

$$
\sqrt{\frac{8}{f}}=\frac{U}{\sqrt{g R S_{0}}}=\frac{U}{u_{*}}(1)
$$

where $u_{*}$ is the shear velocity expressed as $u_{*}=\sqrt{g R S_{0}}=\sqrt{\frac{\tau_{o}}{\rho}}, \tau_{o}$ is the bed shear stress, $U$ is the mean velocity, $R$ is the hydraulic radius of the gravel bed, $g$ is the acceleration due to gravity, $S_{0}$ is the longitudinal slope of the bed, and $\rho$ is the density of water.

Velocity distribution along the flow depth in a two-dimensional channel is based on the consideration of boundary shear, also known as Prandtl-von Karman universal logarithmic velocity distribution, which is defined as

$$
\frac{u}{u_{*}}=\frac{1}{K} \ln \frac{z}{z_{o}}
$$

\section{2}

where $u$ is the point velocity at a height $z$ above the bed, $K$ is von Karman's universal constant, $z_{0}$ is the height above the bed where velocity is considered as zero according to the law of the wall.

For rough turbulent flow in the two-dimensional open channel when grain Reynold number, $\left(\operatorname{Re}^{*}=\frac{\rho u_{*} D}{\mu}\right)$ expressed in terms of the mean diameter of particle $D$ exceeds 70, Keulegan (1938) expressed depthaveraged velocity by integrating Prandtl-von Karman universal velocity distribution along full-depth and approximating full flow depth as hydraulic radius $\mathrm{R}$,

$$
U=\frac{\int_{Z 0}^{R} u d z}{\int_{Z 0}^{R} d z}=\frac{\int Z_{Z 0}^{R} \frac{u_{*}}{k} \ln \frac{z}{z_{O}} d z}{R-z_{O}}=\frac{u_{*}}{K}\left[\left(\frac{R}{R-z_{O}}\right) \ln \left(\frac{R}{z_{O}}\right)-1\right]
$$


In the case of two-dimensional open channel flow, hydraulic radius $R$ is assumed to be full flow depth and $R \gg z_{O}$ (height where velocity tends to zero) and converting base of natural logarithm to logarithm with the base as $10\left(\ln =2.303^{*} \log \right)$, Equation (3) can be simplified as

$$
\frac{U}{u_{*}}=5.75 \log \left(\frac{R}{z_{o}}\right)-\frac{1}{K}
$$

4

Nikuradse (1933), verifying from experiments, has termed that surface absolute roughness is that height $z_{O}$ where velocity tends to zero and expressed $z_{O}$ in terms of the mean diameter of particle $D$, as $z_{O}=\frac{D}{30}$. Thus using, $z_{O}=\frac{D}{30}, K=0.4$ and $\sqrt{\frac{8}{f}}=\frac{U}{u_{*}}$ from Equation (1), the expression for friction factor expressed as

$$
\sqrt{\frac{8}{f}}=5.75 \log \left(\frac{R}{D}\right)+5.94
$$

5

Equation (5) can be written as

$$
\sqrt{\frac{8}{f}}=5.75 \log \left(\frac{R}{D}\right)+E
$$

6

where $\mathrm{E}$ is constant depending upon the cross-section of the channel.

\subsection{Dimensional Analysis for Identifying Parameters Influencing Flow Resistance in Gravel-Bed Channels}

According to Yen (2002), for fluid-carrying cohesionless sediment flowing in a straight channel, the hydraulic resistance is a function of flow characteristics, the channel cross-section's geometry, and the properties of the fluid and sediment. For steady flow, the Darcy- Weisbach friction factor $f$ for a mobile bed channel can be written as:

$f=$ Function of $\left(\nu, \rho, \rho_{S}, D, \sigma, g, S o, U, H, \varsigma\right)(7)$

where, $\nu=$ kinematic viscosity, $\rho=$ density of water, $\rho_{S}=$ density of sediment particle, $D=$ mean diameter of the particle, $\sigma=$ gradation coefficient, $g=$ acceleration due to gravity, $S_{0}=$ longitudinal bed slope, $H=$ Depth of flow, $U=$ Mean velocity of flow and $\zeta=$ cross- sectional shape factor . 
An accurate prediction of the friction factor would require an explicit expression containing all the parameters in Equation (7). However, it can be simplified to make modeling more accessible. The ratio of specific density of sediment $\rho_{s}$ and water $\rho$ is represented by the specific gravity, $G$. In this study, uniformly sized gravel particles are considered; hence, the gradation coefficient, $\sigma$, is almost constant and can be taken out of the above functional relation. The cross-sectional shape factor of a rectangular channel can be represented by width, $W$, and hydraulic radius $R$. Thus, the functional relationship for the friction factor of steady uniform flow with uniformly sized spherical sediment in a rectangular channel can be expressed as

$f=$ Function of $\left(\nu, D, G, g, S_{0}, U, H, W, R\right)(8)$

From the dimensional analysis, these parameters can be clubbed to form six important dimensionless terms, as (1) $\frac{R}{D}=$ Relative submergence depth, (2) $\frac{U R}{\nu}=\operatorname{Re}$ (Reynolds number), (3) $\frac{U}{\sqrt{g R}}=\operatorname{Fr}$ (Froude number), (4) $\frac{W}{H}=\delta$ (Aspect ratio ) (5) $S_{0}=$ longitudinal slope, and (6) $\frac{S_{0} R}{(G-1) D}=\theta$ (Shields number)

Froude, Reynolds, and Shields number are taken into consideration because flow in open channel with bedload transport condition is with a free surface, generally turbulent and moving bed material experiencing shear stress. However, it has been noticed that in the expression of Shields number, two already considered dimensionless terms $\left(\frac{R}{D}\right)$ and $S_{0}$ are appearing. Therefore, the Shields number, $\theta$ has not been considered separately and thus, the above functional relation can be expressed as, $f=$ Function of $\left(\frac{R}{D}, S_{0}, \frac{W}{H}, F r, R e\right)(7)$

In the present study, above selected five non-dimensional terms i.e. longitudinal bed slope, $S_{0}$; relative submergence height $\left(\frac{R}{D}\right)$; aspect ratio $\left(\delta=\frac{W}{H}\right)$; Reynolds number $(R e)$; and Froude number $(F r)$ are considered to be influencing parameters affecting the variation of friction factor, $f$ for the case of mobile bedload conditions. Table 3 presents a wide range of datasets facilitating the analysis to find the effect of various parameters on the friction factor for mobile bedload conditions. 
Table 3

Influencing Parameters for the experimental datasets undertaken in the study

\begin{tabular}{|c|c|c|c|c|c|c|}
\hline Datasets & $\begin{array}{l}\text { Slope } \\
\text { So } \\
(\%)\end{array}$ & $\begin{array}{l}\text { Relative submergence } \\
\text { height }\left(\frac{R}{D}\right)\end{array}$ & $\begin{array}{l}\text { Aspect } \\
\text { Ratio } \\
\delta \\
(W / H)\end{array}$ & $\begin{array}{l}\text { Froude } \\
\text { no. } \\
\text { Fr }\end{array}$ & $\begin{array}{l}\text { Reynold's } \\
\text { No. } \\
\text { Re }\end{array}$ & $\begin{array}{l}\text { Discharge, } \\
Q\left(\mathrm{~m}^{3} / \mathrm{s}\right)\end{array}$ \\
\hline \multirow[t]{2}{*}{ Gilbert (1914) } & $0.62-$ & $6.38-$ & $1.18-$ & $0.86--$ & $14325-$ & 0.0051-- \\
\hline & 2.25 & 27.32 & 12.5 & 1.67 & 73814 & 0.0316 \\
\hline \multirow[t]{2}{*}{ Cassey (1935) } & $\begin{array}{l}0.119- \\
-\end{array}$ & $10.31-$ & $1.39-$ & 0.49-- & 10473- & 0.0047-- \\
\hline & 0.509 & 75.2 & 14.29 & 0.93 & 101812 & 0.099 \\
\hline \multirow[t]{2}{*}{ Mavis (1937) } & $\begin{array}{l}0.155- \\
-\end{array}$ & $6.61-$ & $6.25-$ & $0.58-$ & 7036- & $0.006-$ \\
\hline & 1.01 & 50.57 & 50 & 1.2 & 71782 & 0.078 \\
\hline \multirow[t]{2}{*}{ Bogardi (1939) } & 1.04-- & $4.24-$ & 2.17- & $0.87--$ & 23681- & $0.016-$ \\
\hline & 2.45 & 10.87 & 25.00 & 1.61 & 89381 & 0.064 \\
\hline \multirow[t]{2}{*}{$\begin{array}{l}\text { Ho Pang Yung } \\
\text { (1939) }\end{array}$} & $\begin{array}{l}0.128- \\
-\end{array}$ & $13.81-$ & $1.61-$ & $0.53-$ & 29593- & $0.016-$ \\
\hline & 0.504 & 37.36 & 5.56 & 0.93 & 89833 & 0.069 \\
\hline \multirow[t]{2}{*}{$\begin{array}{l}\text { Meyer-Peter and } \\
\text { Muller (1948) }\end{array}$} & $0.128-$ & $6.06-$ & $1.43-$ & $0.42-$ & $11211-$ & $0.005-$ \\
\hline & 2.27 & 33.53 & 11.11 & 1.47 & 1281043 & 4.613 \\
\hline \multirow[t]{2}{*}{ Paintal (1971) } & 0.13-- & $5.94-$ & $4.35-$ & $0.54-$ & 24853- & 0.02605-- \\
\hline & 1.00 & 61.76 & 14.29 & 1.04 & 193151 & 0.25484 \\
\hline \multirow{2}{*}{$\begin{array}{l}\text { Smart and Jaeggi } \\
\text { (1983) }\end{array}$} & 3.00-- & $3.67-$ & $2.38-$ & $1.42-$ & 19919- & $0.005-$ \\
\hline & 20.00 & 14.14 & 8.33 & 4.57 & 93467 & 0.03 \\
\hline \multirow[t]{2}{*}{ Cao (1985) } & $0.50--$ & $1.30-$ & $2.78-$ & $0.85--$ & 55815- & $0.04-$ \\
\hline & 9.00 & 15.26 & 10.00 & 1.52 & 201308 & 0.19 \\
\hline \multirow[t]{2}{*}{ Graf (1987) } & $0.50--$ & $3.84-$ & $2.32-$ & $0.84-$ & $53764-$ & $0.040-$ \\
\hline & 2.50 & 17.43 & 8.33 & 1.30 & 185294 & 0.205 \\
\hline \multirow[t]{2}{*}{ Rickenmann (1990) } & 7.00-- & $3.04-$ & $2.33-$ & $1.50-$ & $34472-$ & $0.01-$ \\
\hline & 20.00 & 7.85 & 6.25 & 3.93 & 97059 & 0.03 \\
\hline Recking (2006) & $1-$ & $1.97-$ & $2.86-$ & $1-$ & $4588-$ & $0.006-$ \\
\hline
\end{tabular}




\begin{tabular}{|c|c|c|c|c|c|c|}
\hline Datasets & $\begin{array}{l}\text { Slope } \\
\text { So } \\
(\%)\end{array}$ & $\begin{array}{l}\text { Relative submergence } \\
\text { height }\left(\frac{R}{D}\right)\end{array}$ & $\begin{array}{l}\text { Aspect } \\
\text { Ratio } \\
\delta \\
(W / H)\end{array}$ & $\begin{array}{l}\text { Froude } \\
\text { no. } \\
F r\end{array}$ & $\begin{array}{l}\text { Reynold's } \\
\text { No. } \\
\text { Re }\end{array}$ & $\begin{array}{l}\text { Discharge, } \\
Q\left(\mathrm{~m}^{3} / \mathrm{s}\right)\end{array}$ \\
\hline & 9 & 28.19 & 8.33 & 1.8 & 37500 & 0.015 \\
\hline
\end{tabular}

Figure 3 illustrates the effect of these parameters on friction factor, $f$. The four sub-figures show the direct variation of friction factor for four influencing parameters with different bed slope values.

Figure 3(a) shows that for lower bed slopes, there is not much change in the friction factor for mobile beds with the change in relative submergence height $\left(\frac{R}{D}\right)$; but for higher slopes, even a slight variation of $\left(\frac{R}{D}\right)$, causes significant variations in the friction factor. On the other hand, the friction factor appears to show little variation with the aspect ratio, $\delta$ for lower slope, as seen in Figure $3(b)$. Similar observations are made on the effect of Reynolds number on friction factor at low bed slope, but the variations of $f$ at lower slopes due to change in $\mathrm{Re}$ is not much as in the case of relative submergence height as seen in Figure 3(c); where the friction factor increases with the decrease in Re and the change in variation is observed to be similar for different conditions of bed slope. It is observed that there is a power-law variation of friction factor for the Froude number, as seen in Figure 3(c). Thus, from Figure 3, it can be inferred that friction factor $f$ is influenced by selected geometric and hydraulic parameters, i.e., $S_{0} ; R / D ; W / H$; Re; and $F r$.

\subsection{Empirical Flow Resistance Equations.}

In the case for open channel flow where turbulence is fully developed and without sediment transport, Keulgan (1938) proposed the value of constant $E$ in equation(6) as 6.25 for rough channel flow and the expression of friction factor formulated as,

$$
\sqrt{\frac{8}{f}}=6.25+5.75 \log \left(\frac{R}{D}\right)
$$

\section{8}

Manning and Meyer-Peter Muller (1948) examined the flow resistance characteristics in case moving bedload and the friction factor expressed as,

$$
\sqrt{\frac{8}{f}}=\frac{U}{u_{*}}=6.75\left(\frac{R}{D}\right)^{1 / 6}
$$

9

Engelund and Hansen (1966) proposed the following formulation for finding out friction factor with

$\left(\frac{R}{d_{65}}\right)$ as a factor, 
$\sqrt{\frac{8}{f}}=4.27+5.75 \log \left(\frac{R}{d_{65}}\right)$, they defined $f$ as $\frac{U}{U_{*}}=\sqrt{\frac{2}{f}}(10)$

Cao (1985) carried out experiments on different combinations of bed-slope and gravel size and proposed logarithmic formulation for friction factor as

$$
\sqrt{\frac{8}{f}}=3.75+5.91 \log \left(\frac{R}{D}\right)
$$

11

Smart and Jaeggi (1993) proposed the following formulation wherein slope was also incorporated for finding out friction factor as:

$$
\sqrt{\frac{\overline{8}}{f}}=2.5\left[1-\exp \left(-0.05 Z_{90} / \text { So }\right)^{0.5}\right] \ln \left(8.2 Z_{90}\right) w i t h Z_{90}=R / d_{90}
$$

12

Julien (2006) proposed the following formulation for friction factor as:

$$
\sqrt{\frac{8}{f}}=5.75 \log \left(\frac{2 R}{D}\right)
$$

13

Recking (2006) carried out laboratory flume studies by considering various combinations of bed-slope varying from $1-9 \%$ and uniformly sized particle size of $2.3,4.9,9$, and $12.5 \mathrm{~mm}$ to evaluate friction factor, $f$ under equilibrium condition of moving bedload. In no bedload transport condition, it was observed that $\sqrt{\frac{\overline{8}}{f}}$ increases with the relative submergence depth and becomes constant when bedload appears. In the case of high bedload transport, both the bedload and $\sqrt{\frac{8}{f}}$ increases with the relative submergence depth.

Different flow resistance equations were studied for a wide range of flow conditions, and new equations for two different range of relative submergence depth were formulated as:-

$$
\sqrt{\frac{8}{f}}=-1+9.5 \log \left(\frac{R}{D}\right) \text { for } \frac{R}{D} \text { cript }>
$$

$$
\sqrt{\frac{\overline{8}}{f}}=3.6+5.75 \log \left(\frac{R}{D}\right) \text { for } \frac{R}{D}>16.9
$$


On further investigations, Recking et al. (2008) produced expressions for flow without and with bedload transport as:

$$
\begin{aligned}
& \sqrt{\frac{\overline{8}}{f}}=3.6+3.2 \ln \left(\frac{R}{D}\right)(\text { without bedload) (16) } \\
& \sqrt{\frac{8}{f}}=0.67+3.2 \ln \left(\frac{R}{D}\right)(\text { with bedload) }(17)
\end{aligned}
$$

The various expressions for friction factor have undertaken relative depth, shear velocity, hydraulic radius, bed slope, grain characteristics, etc. established according to the respective datasets. This paper attempts to customize as many parameters as possible into a single expression of friction factor by undertaking 774 laboratory flume datasets, as presented in Table 3.

\subsection{Multi-Gene Genetic Programming Based Model for Predicting of Flow Resistance Equations}

Gene Expression Programming (GEP), suggested by Azamathulla, Ahmad, and Ghani (2013), is a search technique that involves computer programs such as mathematical expressions, decision trees, polynomial constructs, logical expressions, etc. GEP was developed by Ferreira (2001) based on generation and evaluation of its suitability and has offered a wide possibility to solve complex scientific problems.

In addition to the standard GP evolution mechanisms discussed, some unique MGGP crossover mechanisms allow the exchange of genes between individuals, called Two-point High-level crossover and Low-level crossover. MGGP provides six mutation methods for the genes, such as sub-tree mutation; mutation of constants; the substitution of a randomly selected input node; substitute a randomly selected constant; setting randomly selected constant to zero or as one.

A functional set may include arithmetic operators ( $+; ; / ; \times ;$ etc), mathematical functions ( $\sin 0 ; \cos () ; \tan ()$; $\ln ()$ ), Boolean operators (AND, OR, NOT, etc.), logical expressions (IF or THEN) or any other suitable functions defined by the user. Since the trigonometric, Boolean, and logical operators would not help in defining a proper mathematical explicit expression in a generalized sense, only the arithmetic, logarithmic and exponential functions are used with constants and the input parameters as variables. GeneXproTools 5.0 is used for modeling the gene expression programming in this study.

The model developed in this study designates friction factor $f$ as the output and the five influencing dimensionless terms in Eq. (7) as input. Four basic arithmetic operators $(+,-, *, /)$ and some basic mathematical functions ( $s q r t, e x, I n$ ) were used as the function set in the model development. Multi-Genic programming, i.e., with three genes and addition as the linking function, is used. A large number of generations were tested. The functional set and operational parameters used in MGGP modeling during this study are listed in Table 5. Bedload experimental datasets used in this study were distributed into both training and validation purposes. Out of the total 774 series of datasets, 545 series of data sets were used 
as training data, and 229 series of data sets were used for validation purposes. To decide about the most appropriate or best MGGP model based on the possible combination of an individual parameter, predicted $f$ derived from five different models or equations are computed using MGGP. In the first model, all the five parameters are considered input to predict the friction factor, $f$. Similarly, four different models are developed by neglecting one input parameter in each case. The performance of each of the models has been evaluated by conducting statistical error analysis for different variations of five models. For this purpose, standard statistical indicators Mean Absolute Percentage Error (MAPE), Root Mean Square Error (RMSE), Mean Absolute Error (MAE), Mean Percentage Error (MPE), and Coefficient of Determination ( $\left.\mathrm{R}^{2}\right)$ for different models have been determined.

Table 5

Functional set and operational parameters used in MGGP Model

\begin{tabular}{|ll|}
\hline Description of Parameter & Parameter Setting \\
\hline Function Set &,,+- , /, , square, exp, In \\
\hline Number of Chromosomes & 30 \\
\hline Head Size & 8 \\
\hline Number of Genes & 3 \\
\hline Linking Function & Addition \\
\hline Fitness Function & RMSE \\
\hline Program Size & 32 \\
\hline Number of Generations & 1197 \\
\hline Constants per Gene & 10 \\
\hline Data Type & Integer \\
\hline Block Mutation & 0.00138 \\
\hline
\end{tabular}

Table 4

Model Sensitivity of different MGGP Models for $f$

\begin{tabular}{|llllll|}
\hline MGGP Models for $f$ & MAPE & RMSE & MAE & MPE & $R^{2}$ \\
\hline$f=F\left(R / D, S_{0}, W / H, F r, R e\right)$ & 0.6047 & 0.0008 & 0.0005 & 0.3555 & 0.9999 \\
\hline$f=F\left(R / D, S_{0}, F r, R e\right)$ & 57.0932 & 0.0427 & 0.0363 & -51.9099 & 0.9045 \\
\hline$f=F\left(R / D, S_{0}, W / H, F r\right)$ & 42.2142 & 0.0446 & 0.0342 & 15.8183 & 0.8478 \\
\hline$f=F(R / D, W / H, F r, R e)$ & 24.5616 & 0.0482 & 0.0269 & -3.3520 & 0.8124 \\
\hline$f=F\left(R / D, S_{O}, W / H, R e\right)$ & 33.1842 & 0.0514 & 0.0329 & -17.6761 & 0.7967 \\
\hline
\end{tabular}


Table 4 indicates the error analysis of the prospective MGGP models for overall data sets. It is observed that higher MAPE, MAE, MPE, RMSE, and lower $\mathrm{R}^{2}$ values are obtained on excluding any one of the dimensionless terms. Thus signifying that each of the five selected dimensionless terms has a significant influence on the friction factor. Hence, the first model in Table 4 is taken as the best model, and Figure 4 represents its expression tree.

The simplified functional relationship is obtained as,

$$
f=\frac{S o}{(R / D) *\left(3.67 F r^{2}+\delta+F r\right)}+\frac{49\left(\frac{R}{D}-S o\right)}{\delta\left\{\left(\frac{R}{D}\right) * R e+\delta^{2}\right\}}+\frac{7.93 * S o}{F r^{2}}(18)
$$

The MGGP has been used to predict the friction factor $f$. The influential parameters derived from the data sets were used as inputs. Figure 5(a) shows the comparison of predicted $f$ versus the target $f$ at the end of the training and found that the coefficient of determination $\left(R^{2}\right)$ is 0.9999 . This indicates that the training of the MGGP model was satisfactory. Figure 5(b) plot the performance of the MGGP model for $f$ at the end of the validation stage; the coefficient of determination, $\left(R^{2}\right)$, is 0.9999 .

\section{Results And Discussions}

\subsection{Assessment of Equations for Calculating Flow Resistance in Gravel-Bed Channels}

The coefficient of determination is possibly a suitable statistical parameter to evaluate the performance of different models. As can be observed in Figure 6 , the $\mathrm{R}^{2}$ value for almost all the researchers is less than 0.688 , even as low as 0.396 for the case of Julien(2006). Whereas, the developed model has a high $\mathrm{R}^{2}$ value of 0.999 . The models by other researchers are established by taking into consideration their respective experimental observations. On the other hand, the proposed model in this paper considers the experimental observation of a vast range of datasets from the literature. Therefore, the proposed model has feasibility over a wider range of data sets.

To evaluate the overall performance of different models, four error analysis and one efficiency criteria were considered. The MAPE, MAE, MPE, RMSE, and $\mathrm{R}^{2}$, computed for each respective friction factor model, and presented in Table 6. 
Table 6

Statistical Error and efficiency criterion analysis of Different Models Used for $f$ (for Global Data)

\begin{tabular}{|llllll|}
\hline Model & MAPE (\%) & RMSE & MAE & MPE (\%) & R $^{2}$ \\
\hline Meyer-Peter and Muller (1948) & 33.1965 & 0.1004 & 0.0473 & -7.4674 & 0.6131 \\
\hline Cao (1985) & 65.7313 & 0.1231 & 0.0778 & 65.7313 & 0.6882 \\
\hline Recking (2006) & 59.0522 & 0.2774 & 0.0751 & -57.5033 & 0.6424 \\
\hline Julien (2006) & 86.4686 & 0.0884 & 0.0661 & -83.9397 & 0.3968 \\
\hline Recking et al. (2008) & 63.9032 & 0.1446 & 0.0578 & -61.6779 & 0.4272 \\
\hline MGGP Model & 0.6047 & 0.0009 & 0.0006 & 0.3555 & 0.9999 \\
\hline
\end{tabular}

Tables 6 shows the error and efficiency values calculated for different models. The MGGP model's performance is observed to be best for friction factor, $f$ with MAPE $0.6047 \%$, MAE 0.0006 , MPE $0.3555 \%$, RMSE 0.0009 , and $R^{2} 0.9999$. The efficiency of any model can be proved when MAPE, MAE, MPE, and RMSE values are nearing zero andR ${ }^{2}$ is close to one. Here, from statistical analysis, the minimum values of errors for and fitness values very close to one were obtained from the MGGP model rather than from the other models. This was done using a large number of datasets (774) from previous literature. The aspect ratio ranged from 1.18 to 50 , relative submergence depth ranged from 1.30 to 37.36 , Reynolds number ranged from $4.588 \times 10^{3}$ to $1.281 \times 10^{6}$, and Froude number ranged from 0.42 to 4.57 . The MGGP model provided a better prediction of friction factor $f$ compared to other models because the MGGP is capable of mapping the complex non-linear relationship between the various parameters involved in the phenomenon. Other models' performance could not found to be satisfactory for the global geometrical and hydraulic input datasets. However, compiling all the influencing geometrical and hydraulic, the MGGP model proved to be the best for friction factor $f$ for bedload conditions. Nevertheless, when all the data are analysed together and compared to the MGGP model, the model is observed to provide promising predictions.

The above analysis provided an overall understanding of the feasibility of different models. It was observed that the expressions for friction factor from the literature have a large error when used in the datasets undertaken. It can be postulated that these models would be valid for a specific range of datasets. Therefore, to understand every model's validity to various datasets, error analysis is carried out for all the assumed datasets of this paper, using the different models. Such a study would provide a generalized understanding of the viability of every model. 
Table 7

Error analysis for individual datasets for $f$

\begin{tabular}{|c|c|c|c|c|c|c|c|}
\hline \multirow[t]{2}{*}{ Datasets } & \multirow[t]{2}{*}{ Error } & \multicolumn{6}{|l|}{ Models } \\
\hline & & $\begin{array}{l}\text { Meyer-Peter } \\
\text { and Muller } \\
\text { (1948) }\end{array}$ & $\begin{array}{l}\text { Cao } \\
(1985)\end{array}$ & $\begin{array}{l}\text { Julien } \\
(2006)\end{array}$ & $\begin{array}{l}\text { Recking } \\
(2006)\end{array}$ & $\begin{array}{l}\text { Recking } \\
\text { et al. } \\
(2008)\end{array}$ & $\begin{array}{l}\text { MGGP } \\
\text { Model }\end{array}$ \\
\hline \multirow[t]{3}{*}{ Gilbert (1914) } & MAPE & 15.1360 & 17.8827 & 84.2929 & 38.3636 & 55.9759 & 0.4964 \\
\hline & RMSE & 0.0118 & 0.0151 & 0.0611 & 0.0367 & 0.0452 & 0.0004 \\
\hline & $\mathrm{R}^{2}$ & 0.2421 & 0.2370 & 0.2337 & 0.2192 & 0.2300 & 0.9987 \\
\hline \multirow[t]{3}{*}{ Cassey (1935) } & MAPE & 38.2349 & 28.6379 & 93.3558 & 38.9634 & 53.5552 & 0.7423 \\
\hline & RMSE & 0.0165 & 0.0138 & 0.0433 & 0.0196 & 0.0275 & 0.0004 \\
\hline & $\mathrm{R}^{2}$ & 0.6562 & 0.6321 & 0.6199 & 0.5725 & 0.6083 & 0.9985 \\
\hline \multirow[t]{3}{*}{ Mavis (1937) } & MAPE & 45.3347 & 42.1387 & 124.0188 & 65.2885 & 85.3740 & 0.7693 \\
\hline & RMSE & 0.0213 & 0.0218 & 0.0652 & 0.0397 & 0.0488 & 0.0004 \\
\hline & $\mathrm{R}^{2}$ & 0.7390 & 0.7544 & 0.7561 & 0.7401 & 0.7549 & 0.9993 \\
\hline \multirow{3}{*}{$\begin{array}{l}\text { Ho Pang Yung } \\
\text { (1939) }\end{array}$} & MAPE & 39.2781 & 31.6388 & 101.9823 & 41.7685 & 62.7025 & 0.7898 \\
\hline & RMSE & 0.0182 & 0.0154 & 0.0481 & 0.0204 & 0.0307 & 0.0004 \\
\hline & $\mathrm{R}^{2}$ & 0.5366 & 0.5209 & 0.5139 & 0.4806 & 0.5075 & 0.9939 \\
\hline \multirow[t]{3}{*}{ Bogardi (1939) } & MAPE & 28.3950 & 33.9933 & 92.9577 & 84.5938 & 82.5097 & 0.5445 \\
\hline & RMSE & 0.0440 & 0.0435 & 0.0972 & 0.0948 & 0.0892 & 0.0009 \\
\hline & $\mathrm{R}^{2}$ & 0.0723 & 0.0799 & 0.0831 & 0.0897 & 0.0860 & 0.9996 \\
\hline \multirow{3}{*}{$\begin{array}{l}\text { Meyer-Peter } \\
\text { and Muller } \\
\text { (1948) }\end{array}$} & MAPE & 11.5125 & 12.1873 & 63.3283 & 22.6590 & 35.6701 & 0.6725 \\
\hline & RMSE & 0.0086 & 0.0097 & 0.0456 & 0.0225 & 0.0303 & 0.0005 \\
\hline & $\mathrm{R}^{2}$ & 0.5171 & 0.5310 & 0.5343 & 0.5285 & 0.5353 & 0.9982 \\
\hline \multirow[t]{3}{*}{ Paintal (1971) } & MAPE & 31.2036 & 26.1616 & 95.9784 & 55.1091 & 64.4136 & 0.8663 \\
\hline & RMSE & 0.0172 & 0.0159 & 0.0653 & 0.0455 & 0.0510 & 0.0008 \\
\hline & $\mathrm{R}^{2}$ & 0.8276 & 0.8458 & 0.8508 & 0.8538 & 0.8535 & 0.9998 \\
\hline \multirow{3}{*}{$\begin{array}{l}\text { Smart \& } \\
\text { Jaeggi(1983) }\end{array}$} & MAPE & 31.2763 & 24.5190 & 53.1115 & 34.8800 & 40.0468 & 0.3148 \\
\hline & RMSE & 0.1043 & 0.0850 & 0.0639 & 0.0594 & 0.0541 & 0.0005 \\
\hline & $\mathrm{R}^{2}$ & 0.7339 & 0.7714 & 0.7843 & 0.8013 & 0.7939 & 1.0000 \\
\hline Cao (1985) & MAPE & 41.6134 & 32.4376 & 106.8013 & 234.0975 & 134.1374 & 0.5006 \\
\hline
\end{tabular}




\begin{tabular}{|c|c|c|c|c|c|c|c|}
\hline & RMSE & 0.2160 & 0.1697 & 0.2644 & 1.1960 & 0.6193 & 0.0017 \\
\hline & $\mathrm{R}^{2}$ & 0.5080 & 0.4327 & 0.3323 & 0.2374 & 0.1670 & 0.9999 \\
\hline \multirow{3}{*}{$\begin{array}{l}\text { Graf \& Suszka } \\
\text { (1987) }\end{array}$} & MAPE & 17.3971 & 18.9069 & 98.8339 & 64.8397 & 76.5165 & 0.5748 \\
\hline & RMSE & 0.0181 & 0.0156 & 0.0833 & 0.0714 & 0.0704 & 0.0006 \\
\hline & $\mathrm{R}^{2}$ & 0.8325 & 0.8667 & 0.8770 & 0.8833 & 0.8831 & 0.9997 \\
\hline \multirow{3}{*}{$\begin{array}{l}\text { Rickenmann } \\
\text { (1990) }\end{array}$} & MAPE & 44.8087 & 32.7396 & 36.6283 & 47.0441 & 35.8345 & 0.2872 \\
\hline & RMSE & 0.1213 & 0.0951 & 0.0765 & 0.1220 & 0.0820 & 0.0008 \\
\hline & $\mathrm{R}^{2}$ & 0.3011 & 0.2837 & 0.2699 & 0.2138 & 0.2513 & 0.9999 \\
\hline \multirow[t]{3}{*}{ Recking (2006) } & MAPE & 56.8061 & 45.5616 & 21.0224 & 32.3027 & 18.9493 & 0.4754 \\
\hline & RMSE & 0.2513 & 0.2068 & 0.0832 & 0.3029 & 0.0933 & 0.0019 \\
\hline & $\mathrm{R}^{2}$ & 0.7637 & 0.7853 & 0.7642 & 0.5523 & 0.7137 & 0.9999 \\
\hline \multirow[t]{3}{*}{ Present Study } & MAPE & 93.0866 & 78.6969 & 168.9435 & 94.8282 & 113.3270 & 26.1156 \\
\hline & RMSE & 0.0280 & 0.0247 & 0.0552 & 0.0320 & 0.0390 & 0.0082 \\
\hline & $\mathrm{R}^{2}$ & 0.8237 & 0.8298 & 0.8307 & 0.8241 & 0.8307 & 0.9650 \\
\hline
\end{tabular}

Table 7 illustrates the error analysis for the different datasets. The datasets of the present experimental study have also been tested with all the friction models, which had revealed that the MGGP model resulted in a comparatively lower value of $26.115 \%$ and 0.0082 of MAPE and RMSE, respectively, while other models have yielded much higher respective values. Further, a relatively higher $\mathrm{R}^{2}$ of 0.965 has been obtained with the MGGP model.

Figure7(a) shows the mean absolute percentage error for the datasets for the different friction factor models The proposed MGGP model is observed to give negligible percentage error compared to the other models where the error varies from almost $11 \%$ to as high as $235 \%$. Figure $7(b)$ shows the root mean square error computed for the different models, where the MGGP model is also observed to give a very negligible error close to zero. Figure 7(c) shows the values of the coefficient of determination for the datasets for different models. It is evident that the MGGP model's predictability is relatively superior compared to the other models with $\mathrm{R}^{2}$ value close to 1 for all the datasets.

\subsection{Application of the proposed MGGP model in a River}

An explicit mathematical formulation can be considered as enhanced if it could reasonably predict the parameters on the field. The proposed MGGP model, developed for predicting friction factor for mobile bedload conditions, is applied to a field study to observe its performance.

River Koina is a tributary of river South Koel in Odisha. This river originates at Bhangaon in the state of Odisha and flows through West Singhbhum district in the state of Jharkhand, India. The river covers a total 
distance of $83 \mathrm{~km}$ before it gives off into the South Koel River. A stretch of the river Koina located approximately $0.5 \mathrm{~km}$ west of Manoharpur Railway Station. is undertaken for the field study. The aerial photograph of the river has been shown in Figure 8. The river, during its course, transports quite a lot of bedload of varying sizes. The mean diameter of the transported bedload is analysed and found to be around $40 \mathrm{~mm}$, which lies in the range of the present study. The channel geometry and other hydraulic features are analogous to the present study for which the stretch of this river is undertaken for the field study.

The field survey was conducted at a straight planform of the river site to determine the discharge at three sections approximately $50 \mathrm{~m}$ apart. A wire rope was attached across each of the cross-sections ( 1 1, S2, and S3) along which the experimental observations undertaken with the help of a boat (Figure 9). At $2 \mathrm{~m}$ intervals, along the cross-section, the depth of flow and depth-averaged velocity was measured using a measuring staff and a Flow tracker. For the measurement of depth-averaged velocity, the average velocity readings at 0.2 and 0.8 times the depth of flow were considered. The discharge capacity of the channel was consequently determined by the Velocity-Area method. The longitudinal slope of the river was measured by taking the reduced levels of various points along the centreline and determined to be $8.046 \times 10 \nabla^{4}$. Sieve analysis was carried out to determine the mean diameter of the bed particles and found to be $40 \mathrm{~mm}$. The measured geometric and hydraulic parameters are illustrated in Table 8 .

Table 8

Geometric and Hydraulic Parameters of River Koina

\begin{tabular}{|c|c|c|c|c|c|c|c|c|c|c|}
\hline Sections & $\begin{array}{l}\text { Depth } \\
\text { (m) }\end{array}$ & $\begin{array}{l}\text { Area } \\
\left(m^{2}\right)\end{array}$ & $\begin{array}{l}B \\
(m)\end{array}$ & $\begin{array}{l}P \\
(\mathrm{~m})\end{array}$ & $\begin{array}{l}V_{\text {Mean }} \\
(\mathrm{m} / \mathrm{s})\end{array}$ & $R / D$ & $W / H$ & $F r$ & $R e$ & $\begin{array}{l}Q \\
\left(\mathrm{~m}^{3} / \mathrm{s}\right)\end{array}$ \\
\hline S1 & 1.325 & 12.12 & 17.1 & 17.52 & 0.707 & 17.30 & 12.905 & 0.27 & $5.73 \mathrm{E}+05$ & 8.58 \\
\hline S2 & 1.284 & 11.64 & 16.5 & 17.07 & 0.760 & 17.06 & 12.850 & 0.29 & $6.07 \mathrm{E}+05$ & 8.86 \\
\hline S3 & 1.235 & 11.54 & 16.7 & 17.09 & 0.746 & 16.89 & 13.522 & 0.28 & $5.90 \mathrm{E}+05$ & 8.62 \\
\hline
\end{tabular}

Field measurements in rivers require the evaluation of discharge capacity, and any proposed method must reasonably perform well in these conditions. Therefore it is necessary to check whether the proposed model can predict the discharge capacity of a stream. Discharge is calculated by employing the developed MGGP model (Eq. 24) for friction factor, $f$ in the Darcy-Weisbach Equation. It is assumed that the modeled friction factor is no longer dependent only on the roughness factor but the other geometric and hydraulic factors incorporated into the MGGP model. Different models analysed in the previous section is applied to the three surveyed sections of river Koina. Table 9 illustrates the error analysis of discharge capacity in terms of MAPE, RMSE, MAE, and MPE. 
Table 9

Error analysis for Koina River

\begin{tabular}{|lllll|}
\hline Model & MAPE & RMSE & MAE & MPE \\
\hline Meyer-Peter and Muller (1948) & 7.903 & 0.760 & 0.683 & -7.903 \\
\hline Cao (1985) & 9.794 & 0.914 & 0.847 & -9.794 \\
\hline Recking (2006) & 6.459 & 0.650 & 0.558 & -6.459 \\
\hline Julien(2006) & 29.39 & 2.569 & 2.556 & 29.398 \\
\hline Recking et al. (2008) & 4.507 & 0.412 & 0.393 & 2.735 \\
\hline MGGP Model & 0.418 & 0.036 & 0.036 & -0.418 \\
\hline
\end{tabular}

The MGGP model is observed to successfully predict the discharge capacity for a natural section, much better than the other traditional models (Fig. 10) with MAPE 0.418\%, RMSE 0.036, MAE 0.036, and MPE $-0.418 \%$ only. It is seen that Recking et al. (2008) exhibited prediction of discharge with MAPE, RMSE, MAE, and MPE of $4.507 \%, 0.412,0.393$, and $2.735 \%$, respectively. The model suggested by Julien(2006) has underpredicted the discharge by $29.39 \%$, while the model proposed by Cao(1985) has over predicted the discharge by $9.79 \%$. The models suggested by Recking(2006), and Recking et al. (2008) have performed well, but the MGGP model is observed to successfully predict the discharge capacity for a natural section, much better than the other traditional models. It is relevant to state that the proposed model is developed by undertaking five geometric and hydraulic parameters and appropriately applied to real cases within the prescribed ranges.

\section{Conclusions}

The present paper proposed a model based on MGGP for the prediction of friction factor in bedload transport conditions. Data from previous flume experimental studies covering a wide range of flow conditions were utilized to develop a model for predicting flow resistance in two-dimensional open-channel flows moving over a mobile bed. The model developed was verified for laboratory experiments and real field situations. This study aims to assess the impact of influential parameters and develop a convincing model for the prediction of friction factor $f$ using MGGP modeling. From the statistical analysis, the effectiveness of MGGP modeling was demonstrated. The main reason for the high level of accuracy lies in genetic programming's capability, which uses a genetic algorithm to solve optimization problems by creating a group of possible solutions to the problem. The comparison of correlation plots for different models shows that predicted values from the MGGP model are fitted very closely with the actual value and with better accuracy. The coefficients of determination, $\mathrm{R}^{2}$ for prediction of friction factor $f$ using equation suggested by Meyer-Peter and Muller (1948), Cao (1985), Recking (2006), Julien (2006), Recking et al. (2008) were $0.6131,0.6882,0.6424,0.3968$ and 0.4272 , respectively, whereas that for the MGGP model was 0.9999 (Figure 6). MGGP model for friction factor $f$ performed the best with $\mathrm{MAPE}=0.6047 \%, \mathrm{MAE}=$ $0.0006, \mathrm{MPE}=0.3555 \%, \mathrm{RMSE}=0.0009$, and $\mathrm{R}^{2}=0.9999$. This result was obtained using representational global datasets existing in the literature for the condition of bedload transport. From the error analysis, it 
can be concluded that the other models could not satisfactorily predict frictional flow resistance. Although the Equation suggested by Cao (1985) and Julien (2006) had a reasonable better RMSE and $\mathrm{R}^{2}$ values, but for the entire global and individual data sets, the MGGP proved to be a more promising model. Therefore MGGP modeling can be used to investigate the framework of one of the important real-world sedimentation problems involved in the river.

The proposed model is valid for the range of datasets undertaken in the study. The application of the proposed model, beyond the range of the parameters undertaken, needs to be performed taking proper precaution. The present model can be further improved by incorporating sinuosity and eddy viscosity as geometric and hydraulic parameters to take a more generalised form for solving real field problems.

In engineering applications, errors in determining governing parameters affect the accuracy of the prediction of flow resistance. Experimentation has inherent errors that cannot be neglected. Thus, to obtain an accurate prediction of the friction factor, precise determination of flow properties such as slope, velocity, and cross-section is required. The variability of the friction factor with different parameters is also essential to an understanding of the process.

\section{Declarations}

\section{Availability of Data and Materials}

All data, models, and code generated or used during the study appear in the submitted article. In detail, data can be found from the relevant literature.

Ethical Approval Not applicable.

Consent to Participate Not applicable.

Consent to Publish Not applicable.

\section{Authour Contribution}

Satish Kumar - Primary author for the manuscript and conducted the entire experimentatal and mathematical modelling.

Arpan Pradhan - Author assisted in applying the Multi-Gene Genetic Programming for Modelling. Jnana Ranjan Khuntia - Author assisted in prviding sound Literature survey and formatting of the manuscript.

Kishanjit Kumar Khatua - Author assited in providing Technical and Language corrections to the manuscript.

Funding Not applicable. 
Competing Interests Not applicable

Conflicts of Interest The authors declare no conflict of interest.

\section{References}

1. Amershi S, IEEE/ACM 41st International Conference on Software Engineering (2019) Software Engineering for Machine Learning: A Case Study. : Software Engineering in Practice (ICSE-SEIP), Montreal, QC, Canada, pp. 291-300. DOI: 10.1109/ICSE-SEIP.2019.00042

2. Azamathulla HM (2012) Gene expression programming for prediction of scour depth downstream of sills. J Hydrol 460:156-159

3. Azamathulla HM, Ahmad Z (2015) Closure to "Estimation of critical velocity for slurry transport through pipeline using adaptive neuro-fuzzy interference system and gene-expression programming" by H. Md. Azamathulla and Z. Ahmad. J Pipeline Syst Eng Pract 6(1):07014004

4. Azamathulla HM, Ahmad Z, Ghani AA (2013) An expert system for predicting Manning's roughness coefficient in open channels by using gene expression programming. Neural Comput Appl 23(5):13431349

5. Azamathulla HM, Ghani AA (2010) ANFIS-based approach for predicting the scour depth at culvert outlets. J Pipeline Syst Eng Pract 2(1):35-40

6. Azmathullah H, Md., Deo MC, Deolalikar PB (2005) Neural networks for estimation of scour downstream of a ski-jump bucket. J Hydraul Eng 131(10):898-908

7. Bathurst JC, Graf WH, Cao HH (1982) Bedforms and flow resistance in steep gravel-bed channels, paper presented at Euromech 156: Mechanism of Sediment Transport. Eur. Mech. Soc., Istanbul, Turkey

8. Bonakdar L, Etemad-Shahidi A (2011) Predicting wave run-up on rubble-mound structures using M5 model tree. Ocean Eng 38(1):111-118

9. Campbell L, McEwan I, Nikora VI, Pokrajac D, Gallagher M, Manes C (2005) Bed-Load Effects on Hydrodynamics of Rough-Bed Open-Channel Flows. J Hydraul Eng 131(7):576-585

10. Cao HH (1985) Resistance hydraulique d'un lit à gravier mobile à pente raide; étude expérimentale. $\mathrm{PhD}$ thesis. Ecole PolytechniqueFederale de Lausane, Lausanne

11. Carbonneau P, Bergeron NE (2000)). "The effect of bedload transport on mean and turbulent flow properties.. " Geomorphology 35:267-278

12. Das BS, Devi K, Khatua KK (2019) Prediction of discharge in converging and diverging compound channel by gene expression programming.ISH Journal of Hydraulic Engineering,1-11

13. Einstein HA and N. L. Barbarossa,(1951), River Channel Roughness, American Society of Civil Engineers,Paper $N^{\circ} 2528,1121-1146$

14. Engelund F, Hansen E (1966) A monograph on sediment transport in alluvial streams. Technical University of Denmark, T. Forlag, editor, p 62 
15. Ferreira C (2001) Gene expression programming: A new adaptive algorithm for solving problems. Complex Systems 13(2):87-129

16. Fisher D, Ling Xu JR, Carnes Y, Reich J, Fenves J, Chen R, Shiavi G, Biswas J, Weinberg (1993) Applying Al clustering to engineering tasks, in IEEE Expert, vol. 8, no. 6, pp. 51-60. DOI: 10.1109/64.248353

17. Gandomi AH, Alavi AH, Mirzahosseini MR, Nejad FM (2011) Non-linear genetic-based models for prediction of flow number of asphalt mixtures. J Mater Civ Eng 23(3):248-263.

DOI:10.1061/(ASCE)MT

18. Gao P, Abrahams AD (2004) Bedload transport resistance in rough open-channel flows. Earth Surf Proc Land 29(4):423-435

19. Giustolisi O, Doglioni A, Laucelli D (2008) determination of friction factor for corrugated drains. In Proceedings of the Institution of Civil Engineers-Water Management (Vol. 161, No. 1, pp. 31-42). Thomas Telford Ltd

20. Hu S, Abrahams AD (2004) Resistance to overland flow due to bedload transport on plane mobile beds. Earth Surface Processes and Landforms: The Journal of the British Geomorphological Research Group 29(13):1691-1701

21. Hu S, Abrahams AD (2005) The effect of bed mobility on resistance to overland flow. Earth Surface Processes and Landforms: The Journal of the British Geomorphological Research Group 30(11):1461-1470

22. Jiao P, Alavi AH (2020) Artificial intelligence in seismology: Advent, performance and future trends. Geoscience Frontiers, Volume 11, Issue 3, 739-744, ISSN 1674-9871

23. Julien PY (2002) River Mechanics, Cambridge University Press, pp 434

24. Keulegan GB (1938) Laws of turbulent flow in open channels, Journal of research, National Bureau of Standards, 21

25. Khozani et al (2017) An expert system for predicting shear stress distribution in circular open channels using Gene Expression Programming, Water Science and Engineering 2018,11(2):167-176

26. Mahdavi A, Omid M (2004) The effect of bed roughness on velocity profile in open channels. River Flow, Napple, pp 295-300

27. Mekhamer et al (2012) Gene expression programming for power system static security assessment,International Journal of Engineering, Science and Technology, Vol 4, no.2

28. Meyer-Peter E, Muller R (1948) Formulas for Bed-Load Transport. IAHSR, Stockholm, pp 39-64

29. Mohammad Najafzadeh J, Shiri GS, Alireza, Ghaemi (2018) prediction of the friction factor in pipes using model tree. ISH Journal of Hydraulic Engineering 24(1):9-15. DOI:

10.1080/09715010.2017.1333926

30. Najafzadeh M, Bonakdari H (2016) Application of Neuro-Fuzzy GMDH model for predicting the velocity at limit of deposition in storm sewers. J Pipeline Syst Eng Pract. DOI:10.1061/(ASCE)PS.19491204.000024906016003

31. Nikuradse J (1933) Strömungsgesetze in rauhen Rohren,Forsch. Arb. Ing. - Wes, 36 
32. Omid M, Mahdavi A, Narayanan R (2003) Effects of bedload transport on flow resistance in rigid boundary channels. IAHR, editor. IAHR, Tessalonic, pp 641-646

33. Peng et al., An improved Gene Expression Programming approach for symbolic regression problems, Neurocomputing Volume 137, August 2014, pages 293-301

34. Pradhan, Khatua (2018) Gene-Expression Programming to Predict Manning's $\mathrm{n}$ in Meandering Flows. Can. J. Civ. Eng. 45: 304-313 dx.doi.org/10.1139/cjce-2016-0569

35. Recking A (2006) : An Experimental Study of Grain sorting effects on bedload. [Ph.D. Thesis.] French engineering university - INSA Lyon

36. Recking A, Frey P, Paquier A, Belleudy P, Champagne JY (2008)" Bed-Load Transport Flume Experiments on Steep Slopes."J.Hydraul. Eng.Vol.134, No.9.

37. Rickenmann D (1990) The bedload transport capacity of slurry flows at steep slopes (Doctoral dissertation, ETH Zurich)

38. Salmasi F, Khatibi R, Ghorbani MA (2012) A study of friction factor formulation in pipes using artificial intelligence techniques and explicit equations. Turk J Eng Environ Sci 36(2):121-138

39. Schlichting H (1979) Boundary Layer Theory, 7th edn. McGraw- Hill, New York

40. Smart G, Jaeggi M (1983) Sediment transport on steep slopes. Nr.64, Mitteilungen der Versuchsanstalt für Wasserbau, Hydrologie und Glaziologie, Zurich pp 191

41. Song T, Graf WH, Lemmin U (1995)). "Uniform flow in open channels with a movable gravel bed.. " J Hydraul Res 32(6):861-875

42. Song T, Chiew YM, Chin CO (1998) Effects of bedload movement on flow friction factor. J Hydraul Eng 124(2):165-175

43. Van Rijn LC (1984a) Sediment transport, Part I: Bedload transport. J Hydraul Eng 110:10, 14311457

44. Vanoni VA, Sedimentation (eds) (1975) " Manuals and reports on engineering practice, 553-587,

45. Wiberg PL, Rubin DM (1989) Bed roughness produced by saltating sediment. Journal of Geophysical Research: Oceans 94(C4):5011-5016

46. Wong M, Parker G (2006) Re-analysis and correction of bedload relation of Meyer-Peter and Muller using their own database. J Hydraul Engng, Submitted 132:1159-1168

47. Wu W, Wang S-Y (1999) Movable bed roughness in alluvial rivers. J Hydraul Eng 125(12):1309-1312 48. Yen BC (2002) Open channel flow resistance. J Hydraul Eng 128(1):20-39

\section{Figures}




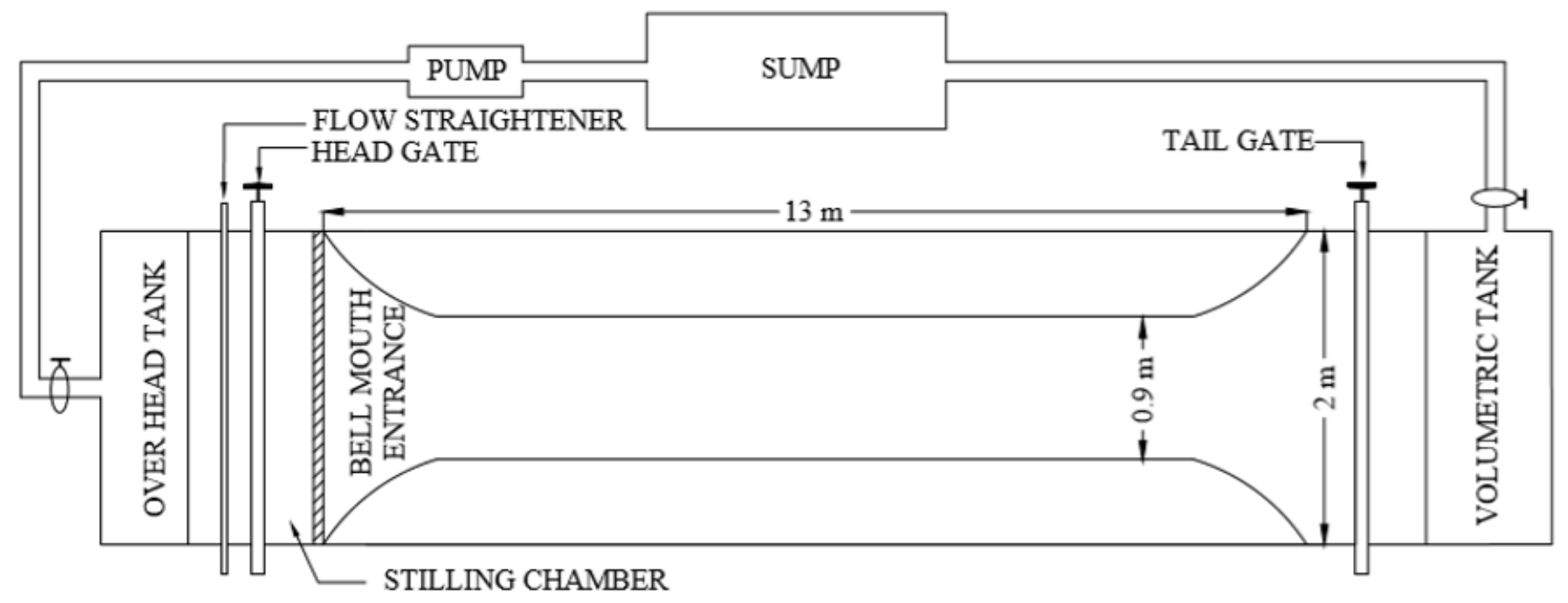

Figure 1

Schematic Layout plan of Experimental Set up, NIT Rourkela

Figure 2

Photograph of Experimental Flume 


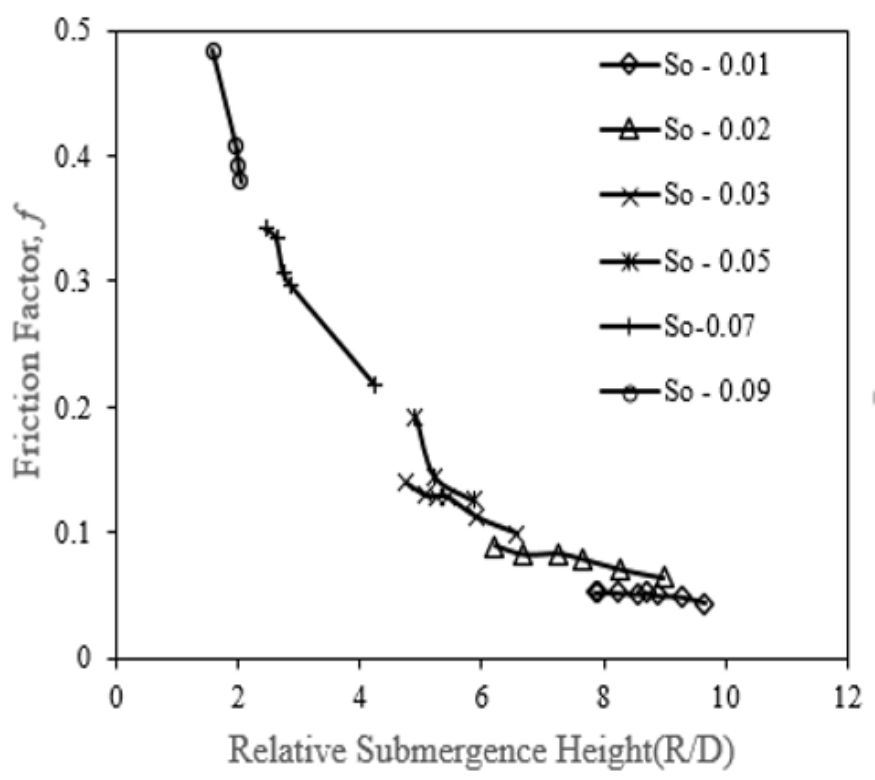

(a) Variation of $f$ with $R / D$

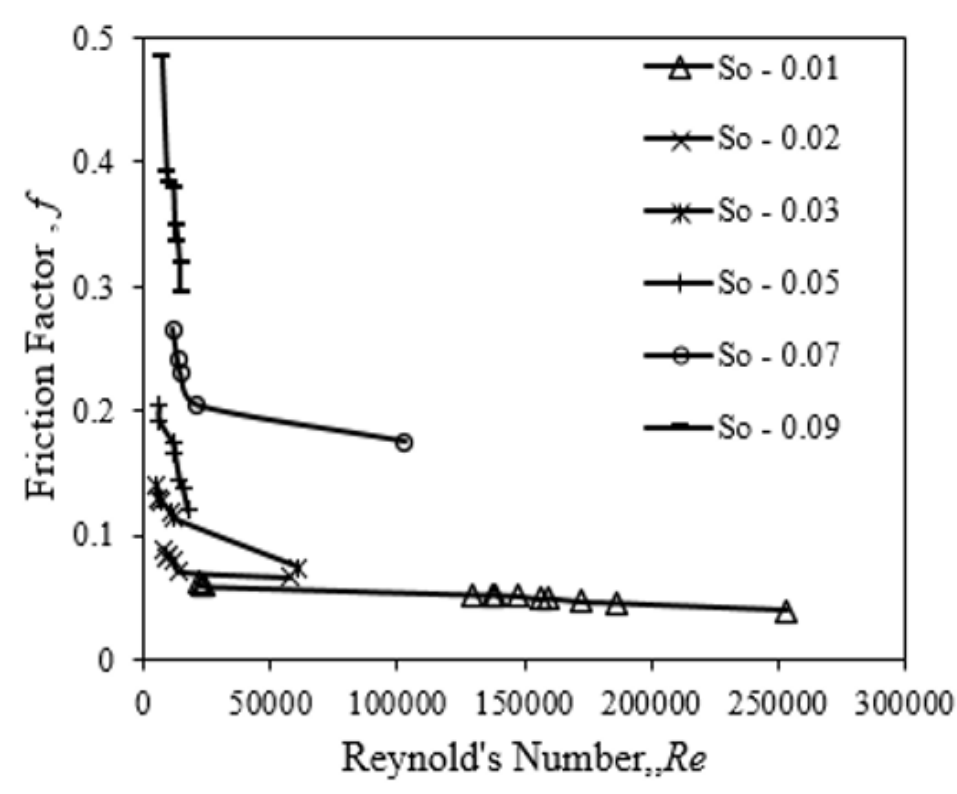

(c) Variation of $f$ with $R e$

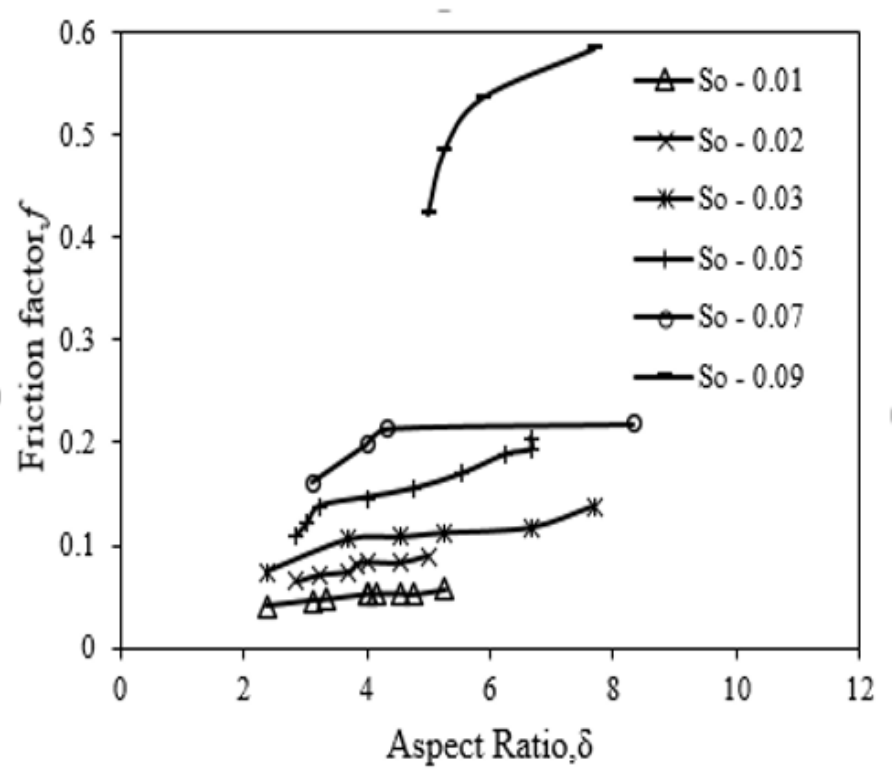

(b) Variation of $f$ with $\delta$

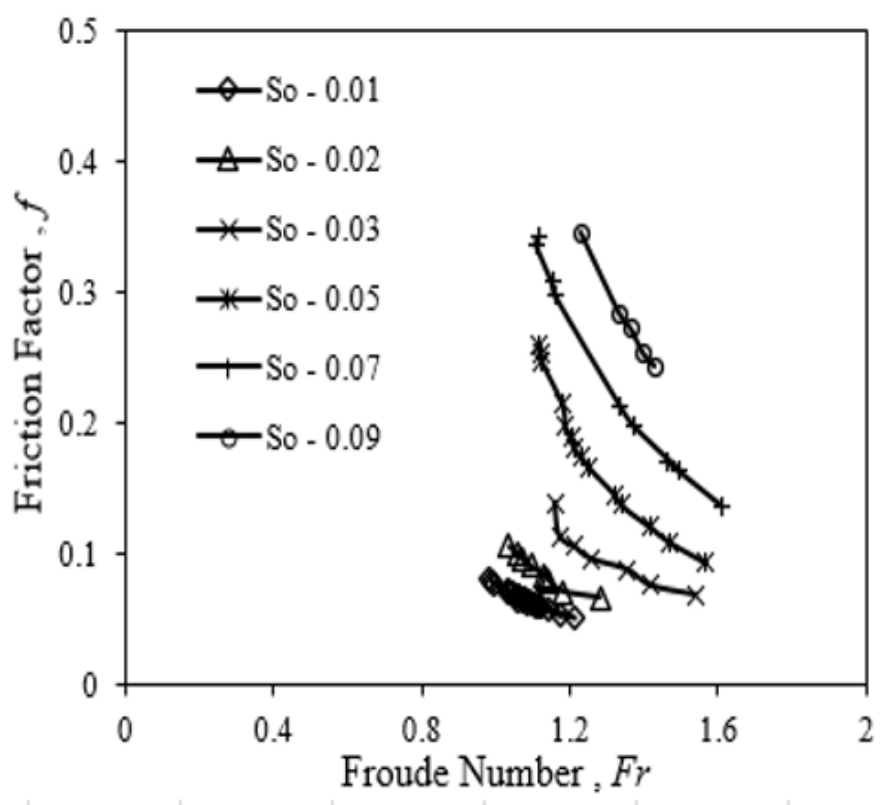

(d) Variation of $f$ with $F r$

\section{Figure 3}

Variation of friction coefficient, $f$ with respect to various influencing parameters 


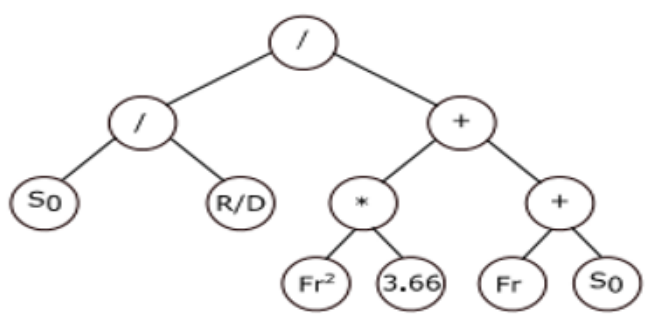

Sub-Tree 1

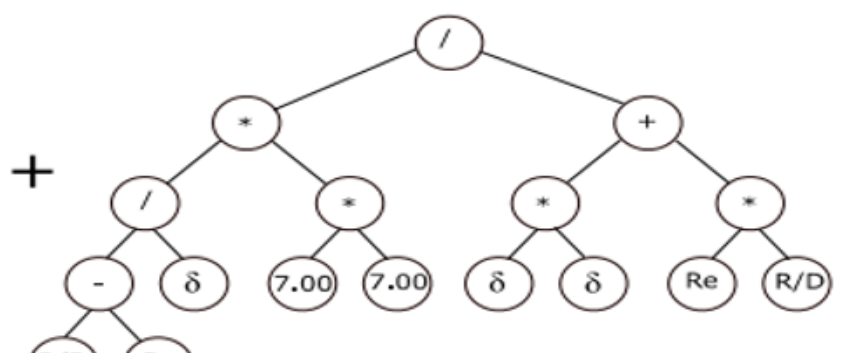

Sub-Tree 2

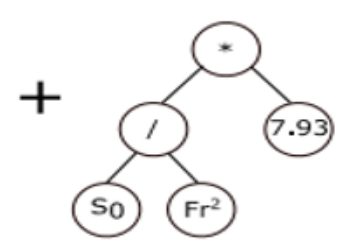

Sub-Tree 3

Figure 4

MGGP Model for Friction Factor
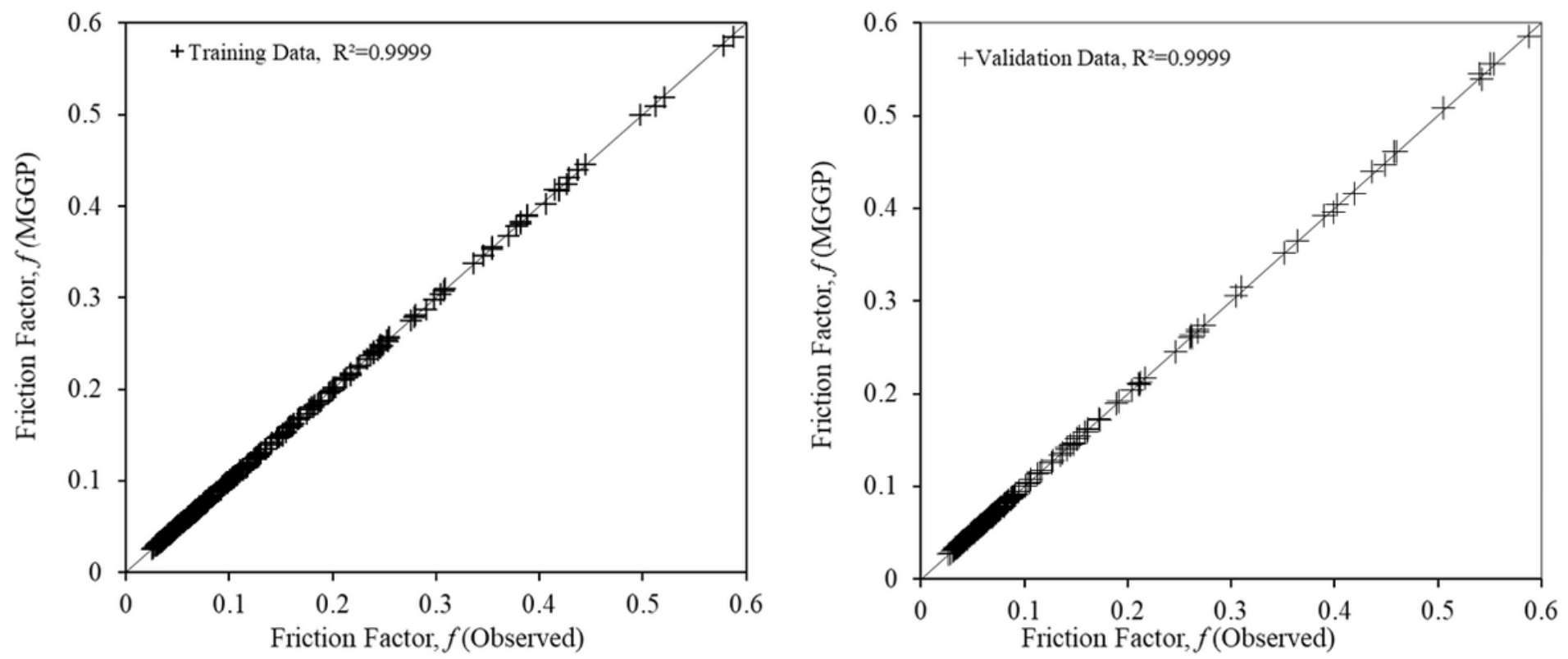

Figure 5

(a). Performance of result at the training stage of the selected MGGP model for $f$

(b). Performance of result at the Validation stage of the selected MGGP model for $f$ 


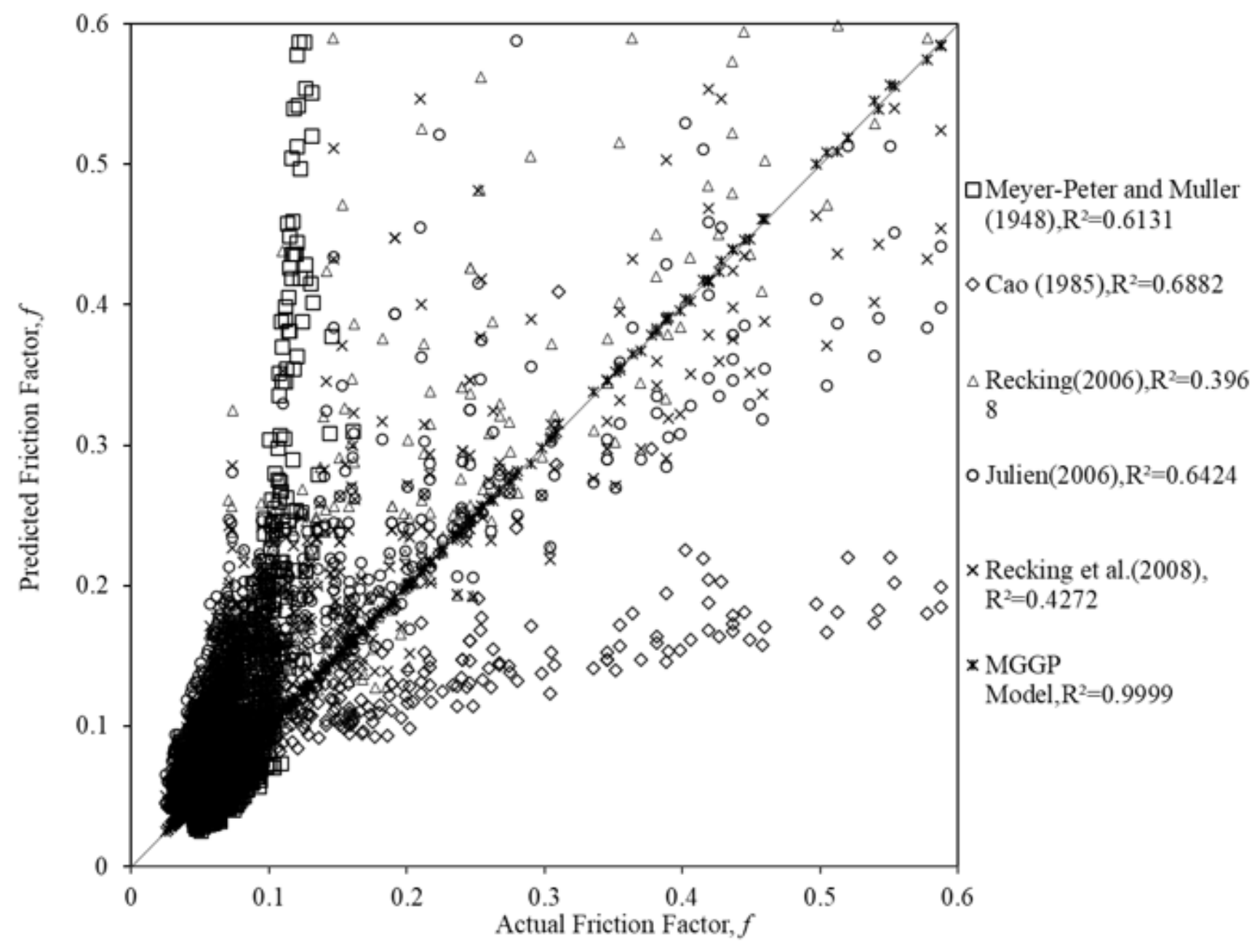

Figure 6

Coefficient of Determination for friction factor by different approaches 


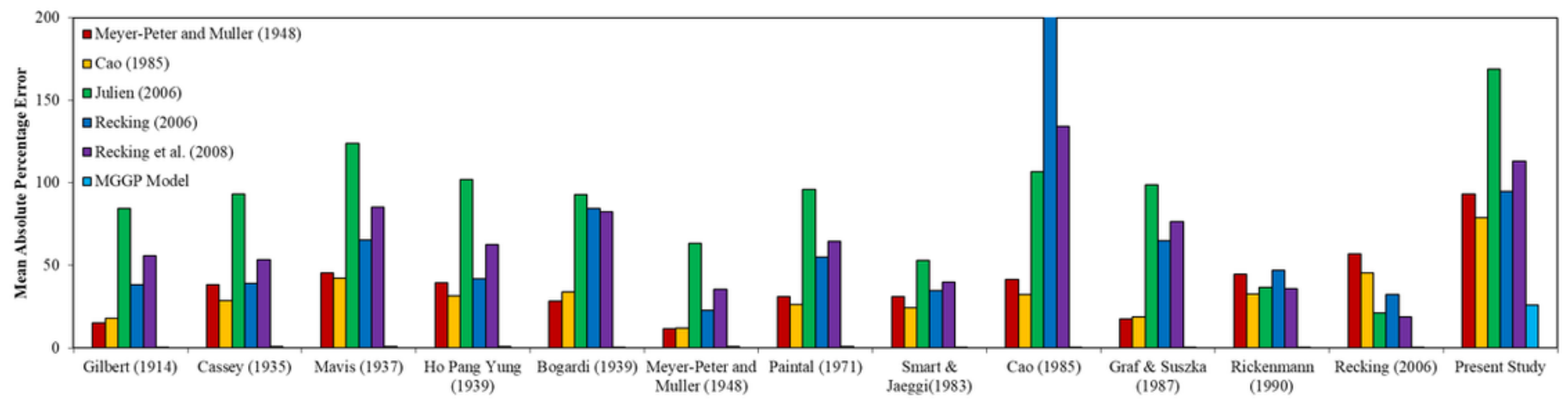

(a) Mean Absolute Percentage Error

Figure 7

Error Analysis for Different Datasets 


\section{Figure 8}

Aerial view of Koina River (India) with location of three measurement sections
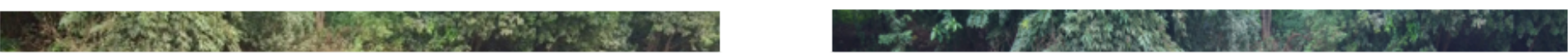

\section{Figure 9}

Sample photographs during velocity measurement and cross-section at Koina River, India 


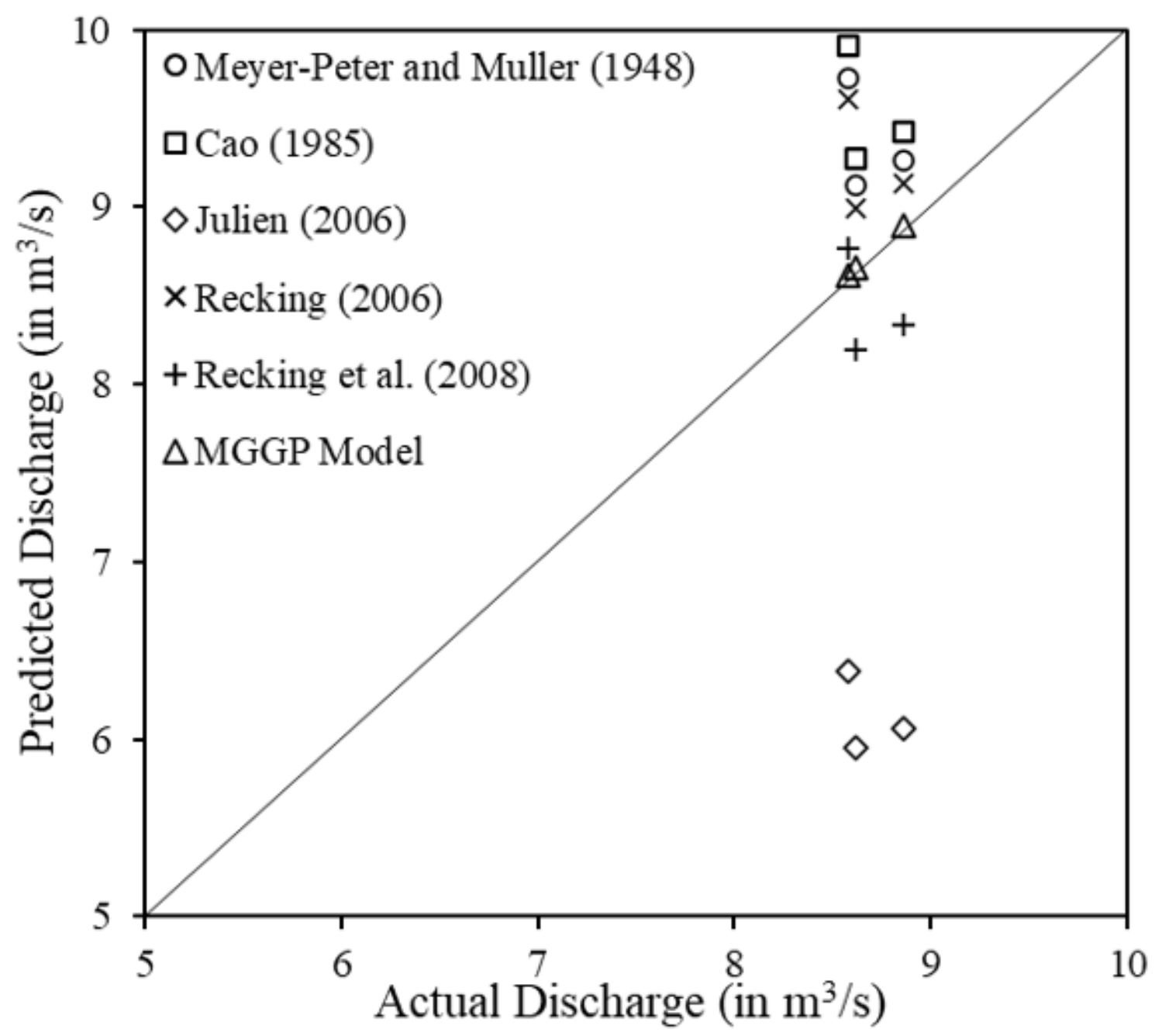

Figure 10

Actual Discharge vs Predicted Discharge by different models for Koina River

\section{Supplementary Files}

This is a list of supplementary files associated with this preprint. Click to download.

- Highlightsforreview.docx 